\title{
Research on Solutions to the Psychological Problems of Postgraduates with Adjustment Disorder-Based on the case analysis of a university
}

\author{
Yang Liu ${ }^{1, a}$, Xiang Wang ${ }^{1}$, Chengbi Mu ${ }^{1}$
}

${ }^{1}$ Beijing University of Posts and Telecommunications, Institute of Network Technology, Beijing, China

aliuyang0506@bupt.edu.cn

Keywords: Adjustment disorder, Psychology, Postgraduate, Case analysis

\begin{abstract}
Adjustment disorder is a common psychological problem for freshmen, but behind the various manifestations of maladjustment to the new environment, there are different deep-seated reasons. Only by thoroughly understanding the source of anxiety and stress, can we "prescribe the right remedy for the problem" and find appropriate solutions. This paper takes the first-grade postgraduate in a "211" university in China as an example to analyze and explore the ways and means to solve the adjustment disorder of the postgraduates.

\section{研究生适应性障碍心理问题解决途径探究 一一基于 A 大学个案分析 刘杨 $1, \mathrm{a}$, 王翔 1 , 牟承碧 1 \\ 1 北京邮电大学网络技术研究院, 北京, 中国 aliuyang0506@bupt.edu.cn}

关键词：适应性障碍；心理；研究生；个案分析

摘要: 适应性障碍是新生入学较常见的心理问题,但在个体呈现出种种对新环境适应不良的表 象背后，都有各自不同的深层次原因，只有深入了解造成学生焦虑、压力的源头问题，才能 “对症下药”, 找到合适的解决办法。本文以国内某 211 高校研究生新生入学实例为分析样本, 探究解决在校生适应性障碍的方法和途径。

\section{1. 引言}

适应性障碍是指在生活方式改变或环境明显变化时产生的、短期和轻度的情绪失调，常 有一定程度的行为变化等，但并不出现精神病性症状，其发病往往与生活事件的严重程度、 个体心理素质、心理应对方式等有关 ${ }^{[1]}$ 。新生入学就是一种典型的生活事件，入学后生活环 境、生活节奏、学习模式、人际关系等都发生了巨大改变, 容易产生适应性问题 ${ }^{[2]}$ 。2010 年, 教育部出台《关于进一步加强和改进研究生思想政治教育的若干意见》明确要求 “要加强研 究生心理健康教育和咨询工作” “3]。当前, 研究生面临的就业、学业、婚姻等多重压力越来越 大, 直接影响身心健康、学业发展和个人成长 ${ }^{[4]}$ 。因此从入学出现的适应性问题为切入, 应 重视研究生群体的心理健康情况。

\section{2. 深入了解学生情况, 全面分析压力来源}

小文是某二本大学本科保研来校就读的学生, 本科期间一直位列专业前五名, 表现优异, 
个性好强。在研究生开学两周后该生出现了严重的失眠、头痛等生理状况, 同时出现了社交 恐惧、幻听等情况。经过多次的深度辅导、咨询评估, 了解到以下三个方面是造成小文适应 性障碍的主要压力源。

\section{1 家人的期望}

小文喜欢马哲类文科专业，有三个亲属在互联网行业就职、创业，事业有成，给小文已 经规划好了未来职业发展的道路, 因此为了迎合家人的期望选择计算机相关专业学习。家人 对于小文表现出来的对专业的不喜欢、学不懂、对环境的不适应十分不能理解，对于医生诊 断的重度抑郁结果和休学建议也无法接受。家人的态度将小文积压多年的自我压抑情绪激发 出来, 是造成小文内心冲突的主要原因。

\section{2 周围同学的压力}

研究生生源三分之一都来自于本校, 很多同学本科期间已提前进入实验室, 形成了一定 范围的交友圈, 对于周围环境适应较快, 小文觉得自己是后来者, 很难融入实验室的群体。 另一方面相较于小文, 实验室的同学专业基础较为扎实, 对于研究生的培养模式适应良好, 学习新技能较快。人际交往的困惑和周围同学对比的落差也是小文压力的主要来源。

\section{3 自我预期的落差}

小文在本科期间一直名列前茅，习惯成为老师、家长、同学们眼中的“优等生”，对于研 究生生活也很有期待, 自我要求极为严格, 不能接受自己对专业知识的一知半解、对导师交 待任务的无所适从，自我预期的巨大落差及暂时无法改变现状的无力感也造成了极大的心理 压力。

\section{3. 多方联动合力帮扶，及时转介专业支持}

基于小文适应性障碍背后的源头压力分析，小文的情况需要多方联动，帮助其剥离压力 源, 重塑信心，建立客观的自我认知。在家长、导师、辅导员、咨询师、医生的共同配合下 小文有了明显的好转, 复学后也顺利的适应了研究生学业节奏。

\section{1 解决生活实际困难和解决心理问题双线并进}

小文生活的实际困难来自于家人的不理解、课业的难度、人际交往的困扰。面对家人的 不理解, 校方除了可从站在共同为学生考虑的角度上与家长沟通外, 也可借助专业咨询师的 力量。通过家庭治疗, 让家长意识到适应性障碍不是一个突发的情况, 是小文多年压抑自己 真实想法迎合家人期望，长期的自我压抑埋下的伏笔，让家人意识到家庭教育中要给予足够 的尊重和成长的空间, 从而正视小文的情况, 遵从医嘱和学生本人的想法, 休学调整、积极 治疗; 面对课业的压力、人际交往的困扰, 借助导师、同学多维度力量, 帮助学生建立生活、 学习的短期目标, 将问题清晰化具体化, 减轻学生的迷茫感。

面对医院诊断的重度抑郁的病症, 需要小文接受专业的药物治疗才能缓解生理上出现的 不适反应, 并不是心理咨询、师生帮扶就能解决的问题, 要及时转介, 并引导学生正视病情, 配合医生遵照医嘱。

\section{2 休学期间定期联络，持续关注做好倾听}

学生休学回家并不是校方对学生帮扶工作的中断点, 有很多休学远离压力源情况好转的 学生复学后仍然不能适应学校的课业生活。对于小文的情况, 休学期应该作为她个人身心成 长的缓冲期, 是本科到研究生的过渡阶段, 既要充分休息配合治疗调整身心状态, 又要根据 学生情况进行适时的引导, 帮助其对返校生活进行规划, 从心态和学习方法上积极调整, 做 好迎接研究生生活的准备。因此在学生休学期间, 还要做好与学生及其家长的定期联络工作, 
对学生的生活情况要有所了解, 做好倾听, 适时引导鼓励。

\section{4. 挖掘内在动机, 搭建成长平台, 帮助重塑信心}

小文入学出现的适应性障碍问题其实也是积压已久的自我意识的觉醒过程。复学后的小 文渴望能够坚持做自己喜欢的事情, 希望能够学习马哲相关的专业, 但现实专业因素的限制 和家人的期望又使得她的想法无法实现, 如何安放她内心的坚持又平衡现有的条件因素是首 要要考虑的问题。根据小文的喜爱, 鼓励并引导她在专业之余投入到思政课程助教等工作中, 找到自己的内部动机, 重新建立自我认知, 找到所爱和所学的平衡点, 重拾信心, 找回自我。

经过咨询评估、医院就诊、寻求家人支持、休学调整、重塑信心等过程，一年的时间，小 文从重度抑郁状态中调整过来, 顺利返校进行科研学习, 对环境适应良好, 在研会、助教工 作中表现突出。

通过小文的实例, 在面对新生适应性障碍心理问题时, 可考虑从以下三个方面开展工作。 首先, 深入的探究问题背后的原因, 可从周围环境、原生家庭、应激事件等方面入手分析。 其次, 科学评估学生的情况, 借助专业的机构或者医生以及家长的多方力量, 提供全面的外 在支持。最后, 要帮助学生树立主观的内在成就动机, 做好回归校园生活节奏的过渡引导, 寻找适时时机创造机会, 给学生营造自我恢复、自我成长的有利条件。

\section{References}

[1] Wei Hao, Xin Yu. Psychiatry[M]. The seventh edition. Beijing: People's Medical Publishing House, 2016:165-166.

[2] Xiquan Zhu, Huifeng Duan, Xuejun Liang. Correlation analysis of recruit's adjustment disorder and the clinical basical scale of MMPI[J]. Prac J Med \& Pharm, 2019, 36(1):6-8.

[3] Xiaolong He. Research on the construction of ideological and political education system for postgraduates under the new situation[D]. North University of China, 2013.

[4] Haiying Liu, Yuanyuan Zhao. Investigation report on psychological pressure of Postgraduate[J]. Journal of Shandong University of Technology (Social Sciences), 2013(4):103-108. 